\section{Teaching Canada for the Nineties}

By Robert M. Anderson

Canadian Studies and the new informadian studies programs should prepare students to use the potential of the "wired
society" for personal improvement. To simply exist in this wired society is not understand it so that they do not simply
become its victims. The Canadian Studies programme outlined in Teaching
Canada for the '80s must be interpreted so as to give proper emphasis to the imrevolution.
The Canada Studies Foundation has The Canada Studies Foundation has
long postulated that the Canadian long postulated that the Canadian
political community has been and con-
tinues to be formed and influenced by a tinues to be of readily identifiable characteristics or basic features that in combination make Canada a unique
country. The most important of these basic features are:

1. Canada is a northern, vast, and regionally divided country. base non-renewable resources.
Canada is an industrial, technological Canada is an industrial, technological
and urbanized society. and urbanized society. ethnic country with two "official
linguistic groups. Canada is exposed to a multitude of exThree poinsts must be noted about these
basic features, particularly by those who debate the content and context of Canadian studies programs. First these do exist. One may add to the list, but these features are an integral component features interact with each other and it is this interaction which most strongly in-
fluences the development of Canadian Society. Third, the impact of each of these features is felt to varying degrees at dif. ferent times and in difterent places within ideal Canadian studies program but an program should ignore these features,
their origin and their continuing impact

on our society.
They form the basis for the argument in
Teaching Canada for the ' $80 \mathrm{~s}$, where

R.M. Anderson is currently Director of
the Canada Studies Foundation. He was previously a member of Memorial
University in Newfoundland and has University in with teacher groups all across articles and monographs on social studies and Canadian studies.
Hodgetts and Gallagher present a set of After raising the major issues involved in teaching about Canada, they proceed to outline a proposal for an optimal program although widely accepted, has also generated further inquiry across Canad studies and its pedagogical implications,
as can be seen at any teachers' conference and in many curriculum guidelines. In turn, this discussion has generated concrete activities. Many curriculum or ly refer to Teaching Canada for the '80s at some point, although they do not
always utilize all its ideas. always utilize all its ideas.
The book is exclusively addressed to the question "What should young Canatry?"' This question arises from two concerns: 1) a conviction that we need mor society as a whole; and 2) a recognition that our society is becoming unbelievably more complex than in the past. Today's
students must exist in an increasingly students must exist in an increasingly
complex society yet their schooling has often failed to prepare them adequately The pedagogical imperative thus become clear: to design a program of Canadian
Studies that will reflect and clarify this complexity while at the same time fostering more positive Teaching Canada for the '80s has made a start. Understandings have been an informed knowledge of Canadian its economic and political systems, and the problems or issues that have been and
will continue to be of continuing concern These understandings emphasize the pluralism and diversity of Canada and the Canada's regional difficulties that cultural and linguistic differences present. One basic premise is that conflict of opinion, controversy and stress are in
evitable in all societies and especially in evitable in all societies and especially in
Canada, but that these tensions can also be a constructive force in any society. At the same time, an overemphasis on our differences in a narrowly Canadian con-
text will obscure that fact that many text will obscure that fact that many
Canadian regional or national issues are and that they transcend purely domestic considerations. In short, we cannot be too be conerned with isses such as population issues such as the tion, world food and water shortages and energy probler
examples. society, the structure and functioning of
This concept of Canadian Studies large-
ly equates them with citizenship education. Initial preparation for citizensh education must begin in the elementary
school and continue through the school program. This can be done by concentrating on those aspects of the environ-
ment - or the basic features - discussed ment - or the basic features - discussea
in Teaching Canada for the ' 80 s tha are appropriate for the early grades each grade level. In later grades the fou separate, but interrelated, components of and Gallagher can be emphasized: the Canadian environment, the Canadian political system, the Canadian economic
system and Canadian public issues. There system and Canadian public issues. Ther
is no one way to do this. The challenge is is no one way to do this. The challenge is
to integrate these components into feasible courses - a not-so-simple challenge particularly when it is maintained that
the present, past and future form three aspects of a good program and that all three aspects must be stressed. upon these five basic features as explained in Teaching Canada for the ' $80 \mathrm{~s}$. Materials have also been developed, par-
ticularly by the Canada Studies Foundation, and the work is continuing. Of greater import, there is some evidence to
indicate that the goals outlined in indicate that the goals outlined in
Teaching Canada for the '800 are being achieved. The major conclusion of surveying almost 11,000 students in ten provinces and two territories was as
follows: "Students included in this surver do indeed possess a basic level of knowledge about Canada and do possess positive attitudes." ( $p$. 36). This conclu-
sion does not mean that reform in Canadian studies education should cease. Far from it, for this is only one study, albeit a large one. The conclusion does allow for
at least limited optimism however. The major conclusions of Hodgetts ${ }^{\prime}$ (1968,
landmark study which was as follows: ... the legitimate national interests
of this country are not being served
by our present Canadian Studies by our present Canadian Studies
programs and that the need for
radical reforms is urgent. Not on ly are the schools failing to serve the interests of the wider society. but the reasonable expectations of
the individual student while he is in school - as distinct from the role he may play as a citizen after
graduation - are not being fulfilled Little reference is made in Teaching formation technologies that are affectin our lives in so many ways - both visible
and invisible, an omission which it-

VOLUME 12, NUMBER 4, 1983 Public Archives of Cal have advanced upon us. $\mathrm{Ob}$ ously, Canadian Studies must still confunctioning of Canada's economic and political systems and the issues that are of continuing concern to Canada. However,
the issue of technology, particularly the integrated into the Canadian Studies program more explicitly than it has been. It
is obviously too importa "What has been called the " $q$ ignored. tion" is going forward, inexorably, day by we lift a finger to control and direct them, we will use and be affected by the new This last phrase, "the new highlights what is perhaps the most important characteristic of the new informa-
tion technology, a characteristic that many people choose to ignore: there is no single new technology; there are several. This is the important point. As Elmes
(1981) has so aptly described it, it is the chronological juxtaposition of a number
of developments in technology that have produced a situtation where each of us will witness a rate of change heretofore
described only in science fiction. These described only in science fiction. These
developments obviously will have profound impacts on society and on education. In turn, the impacts of each will impact one another.
Although the information is reasonably familiar, it is useful to summarize it here, echnological advances are and how revolutionary their implications.
The electronic tube that cost two dollars in 1950 became a transistor that cost ten cents in 1966 . Today, one hundred thousand transistors have been reduced to one
silicon chip which, if it sells for ten sistor to one hundredth of a cent. If the rate of progress of chip technology continues as predicted, an additional occur over the next ten years at no addiCombined with the reduction of cost,
here has been an incredible miniaturiza there has been an incredible miniaturiza-
tion of information technology. Robert tion of information technology. Rober
Noyce, president of INTEL $_{t}$ a leading manufacturer of microprocessors, said in
1978 that his company had the technical capability of putting an IBM 370 on a single microprocesor chip, but he didn't
know if there was a market for such a thing. That chip, actually an improve
ment on the IBM 370 , has been produced Video discs are with us and indeed are being used in education, private industry,
business and the home. With a self. indexing video disc playback unit capable of playing one-half metre discs, an instructor can index and display on a TV se any one of 16 million pages within two to
three seconds. A recent pilot project of

holdings could be stored on video discs.
This involved the storage of a wide range of holdings: prints, paintings, drawing (both artistic and architectural).
photographs (black and white and colour, posive nd negative), paper documents, tures. This project took place at a time when the technology of video disc recor-
ding and playback was still at the proding and playback was still at the prototype stage. Yet all the goals of the proages of holdings were recorded and

played back.
A single wafer-thin disc, half a meter in diameter, can include images of 32,500 pages. Approximately 19,000 discs could store the complete holdings of the Public
Archives of Canada and occupy the space Self-indexing viling cabinet. have been available since 1980 for $\$ 12,000$ to $\$ 15,000$. This price includes minicomputer, video disc player and TV
set. The cost will drop drastically as the proficient and these units go into large scale production. It will then be economically viable to consider them as learning booths, resource centres and ob-

viously homes.
Laser beam self-indexing playback units are now widely used. They have through extended use in the U.S. Air Force. The life expectancy of these discs, because no gramophone-type needle
touches them, is estimated at a minimum 50 years with regular use.

To date, the most phenomenal rate of technologies has been in the microcomIt is old.

cost of microcomputers, their use in the home is increasing, both for recreationa and learning purposes. Eventually, these data banks and to other homes via optic ibres and Telidon,

This home use will impact drastically Tystem. Altention secondary schools in California rely heavily on microcomputers for instrucsities have been heavily involved in ComUntil recently, most educational com puter uses have been on time-sharing systems with per terminal capital costs of
$\$ 10,000$ to $\$ 20,000$. Personal microcom puters of equal capability are available to-
day for $\$ 1,000$ to $\$ 2,000$ and the cost is The decreasing cost brings this enorThe decreasing cost brings this enor-
mously powerful technology within the ANADIAN JOURNAL OF EDUCATIONAL COMMUNICATION gram and use microcomputers is becom
ing as important as being able to read, A single glass fibre with the diameter. sations, tens of thousands of data messages, or 50 million bits per second in short, it has enough capacity to carry Vancouver in one hour. Linked to
satellite transmission, the carrying speed

is increased again.
Eventually, optical technology will
utilize the visible light laser which will permit a carying capacity of 100 million times today's fibre optics.

Videotex is one of several terms used to tion in graphic or written form on a video screen (TV).

Canada's entry into this field. Develope by the Communications Research Centr munications, Telidon is the most generation videotex system in the world ability. This high resolution is a structions which describe graphic images as basic shapes, thus permitting their
combination on the same frame with termaterial.

hed via a special terminal which utilizes an alphanumeric free-form graphic creation. The system scale in addition to a number of special $\mathrm{e}$ fects such as polka dots. No special quired to input graphics.

Large scale trials are now underway Alberta, Manitoba, Ontario, Quebec,

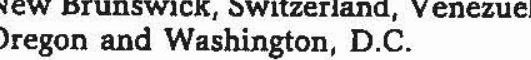
Once one accepts the premise that evitable, then the rationale for the federa becomes obvious. If Canada is not to continue to be relegated to branch plant Society, then Telidon must succeed. and economic sovereignty are closely inked to our ability to control the har

software and data banks.
At present, Telidon is very much plains why the telephone carriers and terested in developing educational pro-

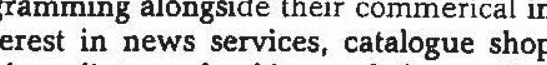
ping, distance banking and the cashles This also highlights the need, once the
Socity premise of inevitability is accepted, for 
involved in the decisions surrounding the ence carriers and industrial interests is self-evident. As indicated earlier, it is the
chronological juxtaposition of these echnological developments which ar creating an extremely accelerated rate of most writers in the field of "high
technology" when he describes the

resulting effects.
This (change), in turn, will impact

on education not only in terms of

methods of delivery but also in
terms of the subjects taught. percentage of time spent in physical plant; the degree of in-
terpersonal reaction; thought processes; problem-solving processes;
and so on. One of the most imporability to relate disparate pieces of

linkages. Power will increasingly
rest with individuals who know
how to access information and to

synthesize it. (p. 3 .

synthesize it. (p. 3).
If Elmes is correct, and I believe that he is, the participant at a recent Compute Aided Learning Workshop who stated
"As far as I know, people never had so many debates on chalk education, but i of Canada, 1981, p. 32) has surely underestimated the potential impact of
the new technologies. The new the new technologies. The new
technologies represent alternative aids to teaching. However, these alternative aids
are so unbelievably more complex than chalk that many debates are not only necessary, they are vital to the survival of
the education system. It follows, therefore, that they were also crucial to the future of Canadian Studies.

that that we must teach students the
knowledge, skills and values that will enable them to compete in an ever increasing complex society. The pressure
is infinitely greater as a result of the All indications point to the fact that by the 1990 's, technological advances that we consider science fiction today will be commonplace. Canadian Studies
educators must prepare students to cope Hopefully, a Canadian Studies program that acknowledges the reality of the "quiet evolution" can utilize that know-
ledge to improve the program and its
delivery. Students must be taught the skills necessary to use the potential of
what has been referred to as a "wired society" for personal improvement. $\mathrm{Ob}$ viously, many important subjects within way.
More than this, however, it is imperative to teach students about the com- munications revolution, so that they is level, PAC MAN diseas now documented in medical journal puter technology has become a part of everyday life in Canada. Furthermore, classroom in few classrooms in calculators or multi-function digital wa ches not be found. When one also con siders interactive teaching machines in oys, electronic arcades and Star Wars robots, it is clear that the electronic revolution is commonplace to today's
children. More complex than even these (1981) is ics, as desctred by Ryan (1981).
another illustration of the growing complexity of our society. Telematics - the
transmission of information over transmission of information over
distance - is the logical result of the juxtaposition of all the technologies. According to Ryan, telematics signifies the merger of information, information technology and communications. It is a com-
bination of subject matter, as expressed in language; of computers and computer
technology; and of communication syslems such as telephones, radios, televsions and telecommunications linkages. Dis benefits to Canada's national sovereignty, to privacy and access to information. present time. That they should be, and presenting the most important of Canada's basic features as described by Casking features to the implementation of the new information technologies.
Canada is a northern, vast, and regionally divided country. . Canada has a broad natural resource base composed of both $r$

3. Canada is an industrial, technological and urbanized socie $y$.
Canada is a culturill

ethnic country with two historicaltpredominant linguistic and cultural 5. Canada is exposed to a multitude of external economic, political
cultural influences. Some questions that are now relevan are: How "northern, vast and regional
divided" need we be given the potential divided" need we be given the potential
of instant interaction between our home and anywhere in Canada? Will our resources be better controlled given the increasingly more sophisticated
power to predict as a result of our current computer technology? Will our "industrial, technological and urbanized" society enable Canada to
become a leader in the field of high
technology?
Will our "culturally diverse, multi-

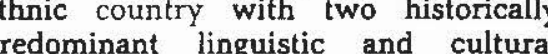
resups" become more or less diverse as

Will the "multitude of external fluences" that Canada is exposed to overwhelm us as a result of the impact of the outside Canada's territorial borders?
The These questions, linking Canada's basic lustrate the potential impact of telematics, both positive and negative, on
Canadian society. They also illustrate how technology and its present and component of a Canadian studies course. It is possible to continue and design an entire curriculum around these questions,
an exercise that likely would be worthIf "PAC MAN disease" and certain recent decisions concerning Canadian content on Pay TV are any indication, there
is reason for pessimism concerning the
"benefits". Canadian citizens will derive from current technological advances. Without considering the issue of the use
of technology for Canadian Studies of technology for Canadian Studies
endeavours lalthough it is difficult to im. agine teaching this topic without the use include the "new information technologless", "telematics", "the wired city", "the
electronic highway", or any other phrase one wishes to utilize in any Canadian
one studies curriculum. Increased knowledge
is vital. A long-standing assumption of the Canada Studies Foundation is that inreased knowledge about Canada will of our society and assist a person to postively and actively participate in it. plies more than simply coping in a com-
plex technological society (although as has been stressed repeatedly that might be difficult enough), it implies the education of a person who is able to make the very survival of our country as we know it. Canadian Studies should prepar for these tasks. As one of the authors of remarked: "It is not teaching Canada for the eighties that should be concerned with, but
nineties."

REFERENCES

Elmes, $R$, An overview of the new infor-

mation technologies. Canadian
Studies Bulletin, March, 1981, 1-4.

VOLUME 12, NUMBER 4, 1983
Hodgetts, A.B. What culture? What
heritage? Toronto: OISE Press, 1968 . Hodgetts, A.B. \& Gallagher, P. A survey of elementary and secondary
pupils: Their knowledge and attitawa: Department of the Secretary of tions Policy. December, 1981, Science Council of Canada. Policy issues ceedings of a workship spg: Proceedings of a workship sponsored
by the Science Council of Canada

Media News
Continued from page 8

that our awards are gaining recognition as
a sign of quality in Canadian educational media productions. In Winnipeg, the CBC-TV outlet presents a weekly series
entitled "Manitoba Filmmakers". Films are chosen on several criteria, one of
which is the AMTEC Media Festival Award. And in Toronto, the University of catalog makes specific mention of the
AMTEC awards.

NFB Reorganizes Distribution Offices The National Film Board announced today that it will close eight of its thirty
distribution offices as part of an overall plan to reduce administrative costs. During the next two years the offices in
Chicoutimi, Saskatoon, Trois-Rivières, Thunder Bay, Kingston, Corner Brook, be closed, as well as NFB offices in Chicago and Sydney, Australia.
The funds saved will be channeled into The funds saved will be channeled into
the development of new communication systems such as video cassette and cabletinued relevance and quality of NFB According to William Litwack, Director
of Distribution, the reorganization will affect 20 employees "but we have been planning the consolidation of our services
for the past year, and will be able to offer most of our staff comparable positions in
other NFB offices. We will work closely with employees who are unable to relocate to ensure that they leave the Film
Board under the fairest conditions NFssible." be encouraged to receive films by mail rom the nearest NFB office. wack said "'and we reult decisions," Litamount of personal contact with our film borrowers will be diminished, but we will do everything we can to maintain close
contact with the public and to provide ef-

In connection with the foreign offices will be transferred to our offices in New York and Los Angeles and film distribu-
tion in Australia and the Far East will be This reorganization leaves us with 22

CANADIAN JOURNAL OF EDUCATIONAL COMMUNICATION distribution offices in Canada and 4 inter-

Office Date Closing Clients will be Chicoutimi August 1983 served from Saskatoon September 1983 Regina
Trois-Rivieres October 1983 Montreal Thunder Bay October 1983 Winnipeg $\begin{array}{lll}\text { Kingston } & \text { March } 1984 & \text { Ottawa } \\ \text { Corner Brook } & \text { August 1984 } & \text { St. John's }\end{array}$ Hamilton November 1984 Toronto Sydney, N.S. January 1985 Halifax
Chicago April 1984 New York and Los $\begin{array}{rr}\text { Sydney, Australia } & \begin{array}{r}\text { Angeles } \\ \text { September } 1983 \\ \text { Montreal }\end{array}\end{array}$ NFB Update

One of the priority items at the meeting
of the National Film Board's Board of Trustees in Halifax, June 17 and 18, was to review the recent decision to close
eight of the Film Board's Canadian were destinated to close during the next two years are Chicoutimi, Corner Brook, Thamilton, Kingston, Saskatoon, Sydney,
Thunder Bay and Trois-Rivieres. "Due to strong public reaction and the fected, we felt a review of the situation was called for," said Government Film
Commissioner and Chairman of the Board James Domville. "During the past of letters and thousands of signatures various groups that sprung up to protest his decision after the closings were anour users clearly shows that the NFB is playing a crucial role in the In the light of the public response, the
Board of Trustees directed the ment of the NFB to modify implementation of the decision to close the eight of thes. Mr. Domville is pleased to say that open until such time as the NFB has bee able to establish adequate alternative arrangements to serve the communities or
until the new policy directions for the Film Board have been accepted by government and announced. In eithe
case, the NFB will ensure that the specialized audiences in the community
are adequately served by our films. national offices, which will continue to
serve our clients $s_{\text {, Litwack said. }}$
Committee on Computers and Proceedings P8116.

, S.L. Microelectronics today of the Chairman An. Statement 1982. Ottawa: Science Council of
Canada, 1982.

Conference on Instructional echnology

"Computer Technologies for Produc-
tive Learning" is the theme for the Fourth Canadian Symposium on Instructional tochnology which will be held on Oc-
tober 19-21, 1983 at the Westin Hotel, Winnipeg, Manitoba.

This series of symposia is sponsored by the Associate Committee on Instructional Council of Canada for the purpose of in-
Cochnolong forming the academic and business comaided learning technology and their

This Fourth Symposium is designed for
education and training professionals and others interested in computer-aided learning for the entire population - from the Topics of the current Symposium
Ton

Computer-assisted training and retraining for business, industry and government.
- Within the educational context:
learning with, from and about

computers.
Computer awareness and literacy in schools and society. Productivity improvemen

methods.
Productivity analysis.

- Systems technologi.

- Systems technology.
- Equipment and language

A circular containing a list of papers
stards.

we presented and registration informatio tequed in receiving
requested to contact:

Ken Charbonnea

Conference Services Office

Ottawa, Ontario, Canada K1A OR6

Telephone: (613) 993-9909 or
993-9628 Telex: 053-3145

Bell and Howell Draw

At the recent AMTEC conference in
Montreal, Dr. Gary Boyd drew the luck winner of the Bell and Howell draw. Ringmaster II was

Steven Counter
Lakeshore School Board
Pointe Claire, P. 